\title{
HUME E $O$ SENSO DE PROBABILIDADE
}

\author{
Don Garrett ${ }^{1}$
}

RESUMO: Na psicologia cognitiva de David Hume, o conceito de PROBABILIDADE faz parte de uma família de sensoconceitos que também incluem os conceitos de AZUL, SAGACIDADE, BELO, VIRTUDE e CAUSA. Cada um deles é obtido através (i) da ativação de uma sensibilidade primitiva, (ii) da consequente formação de uma "ideia abstrata", (iii) da adoção de um "padrão de juízo" juntamente com "regras para o julgar"; e da atribuição de relações inferenciais. $O$ desenvolvimento do conceito de PROBABILIDADE a partir do "sentimento de crença" também possibilita a obtenção do conceito de VERDADE PROVÁVEL, que, assim como os de BELO e VIRTUDE, funciona como um conceito normativo. A compreensão resultante da normatividade epistêmica humeana produz implicações diretas para seu exame do ceticismo.

PALAVRAS-CHAVE: David Hume; Probabilidade; Psicologia Cognitiva. 
"A imaginação, segundo eu mesmo admito, é o juiz último de todos os sistemas filosóficos." Assim escreve David Hume no Tratado da Natureza Humana (T 1.4.4.1). ${ }^{2}$ Mas como pode ele tomar a imaginação - amplamente considerada, dentre todas as faculdades, enquanto fonte de capricho e ilusão - como este último árbitro? Além disso, uma vez garantido esse papel crucial, de que maneira pode permanecer seguro de que sua própria filosofia experimental assenta-se, conforme reivindica, sobre um "fundamento sólido"? (T Intro. 7) Estas são as questões centrais que proponho examinar. As respostas para elas resultam em importantes implicações para a epistemologia de Hume e, de maneira ainda mais ampla, para a epistemologia humeana.

Minha resposta à primeira questão será que a imaginação humeana funciona como o juiz último dos sistemas filosóficos, na medida em que julga sua verdade provável, e que assim o faz porque ela inclui o que chamarei aqui de senso de probabilidade. ${ }^{3}$ Minha resposta à segunda, será que Hume acredita que um sistema com suficiente probabilidade de ser verdadeiro pode ser considerado como epistemologicamente bem fundado e que sua própria filosofia atende esse quesito.

Explicar e defender tais respostas exigirá a elaboração de um considerável preâmbulo. Em primeiro lugar, desenvolverei, no contexto da psicologia cognitiva de Hume, paralelos entre um conjunto de conceitos centrais à sua filosofia. Tais paralelos, embora às vezes compareçam apenas de maneira implícita, estão frequentemente explícitos em seus textos. Eles começam com os conceitos de cores, sons, sabores e odores, assim como de calor e frio, mas se estendem aos conceitos de humor ou sagacidade, de belo e feio, de virtude e vício, e, conforme discutirei adiante, de probabilidade. Os conceitos específicos acima mencionados 
são aqueles que Hume trata como "derivados" de um "senso", isto é, de uma sensibilidade ou capacidade primitiva de possuir um tipo específico de resposta mental sentida [felt mental response] devido a um estímulo. Chamamos tais conceitos, para usarmos uma expressão contemporânea, de conceito "dependente-deresposta" [response-dependent concept]. Para alguns, de fato, a própria noção "dependente-de-resposta" foi parcialmente inspirada pela comparação mais ampla, conduzida por Hume, das qualidades "secundárias" (tais como cores, sons, sabores e odores) com as qualidades morais. Assim, uma maneira de expressar uma de minhas interpretações principais seria dizer que, para Hume, o conceito de probabilidade é também um "dependentede-resposta". No entanto, discussões contemporâneas sobre o assunto têm levado a caminhos não-humeanos os mais variados e demasiadamente complexos para serem examinados aqui. A fim de evitar complicações desnecessárias, empregarei, ao invés disso, o termo mais estritamente etiológico e, de alguma maneira, mais humeano: "baseado no senso" [sense-based].

Em segundo lugar, esboçarei brevemente a visão de Hume sobre como certos conceitos (tais como belo, virtude e verdade) podem contemplar o caráter prescritivo ou avaliativo de normatividade. Isto, por sua vez, ajudar-nos-á a perceber de que maneira o conceito de verdade provável pode ser empregado em juízos epistemicamente normativos. Ao entendermos o tratamento concedido por Hume ao senso-conceito [sense basedconcept] e ao conceito normativo, estaremos em condições de responder nossas duas perguntas sobre o papel da imaginação no julgamento dos sistemas filosóficos e também de extrair consequências a respeito de três tópicos na epistemologia: os princípios epistêmicos a priori; a diversidade epistêmica irrepreensível; e a oposição ao ceticismo epistêmico global. 


\section{SENSO-CONCEITOS}

Tanto para Hume quanto para Hutcheson, a mente faz uso de muitos sentidos. Naturalmente, aí estão incluídos os cinco sentidos externos, por meio dos quais distinguimos qualidades como quentura, doçura, fetidez, agudeza e brancura, mas não apenas isso. Passando, por assim dizer, do visível ao risível, Hume também segue Hutcheson ao descrever o humor ou a sagacidade enquanto aquilo que é detectado por um "senso", comumente chamado de "senso de humor". O belo e o feio, assinala, são discernidos por um "senso de beleza" que denominamos de "senso estético". Contra os opositores racionalistas, a exemplo de Samuel Clarke, Hume defende que virtude e vício são reconhecidos por um "senso de beleza moral" ou "senso de virtude" que ele também designa de "senso moral".

Podemos distinguir quatro elementos na explicação de Hume sobre o desenvolvimento pleno de um senso-conceito, elementos que podem ser considerados como estágios ou processos superpostos. O primeiro deles, podemos chamar de ativação repetida: a produção recorrente, em resposta a estímulos, da resposta mental constitutiva de um senso. Para os sentidos externos, esta ativação normalmente requer a influência causal de corpos sobre os órgãos dos sentidos que estejam em funcionamento e culmina no que Hume chama de "impressões de sensação". Para o senso de humor, ideias normalmente transmitidas por palavras ou ações produzem "impressões de reflexão" particularmente prazerosas. Quanto ao senso de beleza, certos objetos, eventos ou composições são percebidos pelos sentidos externos ou considerados na imaginação e provocam, seja os prazerosos "sentimentos do belo", seja os dolorosos "sentimentos do feio". No caso do sentimento moral, 
a experiência ou o pensar sobre o traço mental característico de uma pessoa - considerada quanto às consequências específicas para aqueles afetados por essa experiência ou pensamento causa tanto os prazerosos "sentimentos de aprovação moral" (vale dizer, os "sentimentos de virtude") quanto os dolorosos "sentimentos de desaprovação moral" (isto é, os "sentimentos de vício").

O segundo elemento é a generalização inicial: a formação natural do que Hume usualmente chama de "ideia abstrata", "noção abstrata" ou apenas de "noção", suscitada pela semelhança entre os muitos casos de uma resposta característica. O pensamento, segundo Hume, pode ocorrer na ausência das ideias abstratas, sendo uma ideia não-abstrata particular a forma mais básica de representação mental. Do mesmo modo, a forma mais básica da crença é uma ideia não-abstrata particular com suficiente "vividez", também designada de "força e vivacidade", que funciona como modelo mental na orientação do comportamento, como também do pensamento. Uma crença básica pode consistir, por exemplo, na imagem vívida e complexa de um faisão no arbusto, que orienta as atitudes de um cão ou de um caçador. No entanto, pensar genericamente exige que se tenha uma ou mais ideias abstratas: ideias que, enquanto inteiramente determinadas em sua própria natureza, logram a generalidade da representação através de suas associações com outras ideias.

De acordo com Hume, as ideias abstratas originam-se quando um número de ideias diferentes mas assemelhadas tende naturalmente a suscitar uma resposta verbal comum a partir da qual elas passam a ser conjugadas pelo hábito. Novas ocorrências da resposta verbal tendem assim a suscitar uma ideia determinada comum ou particularmente relevante, ao mesmo tempo em que "reaviva o costume" ou hábito de formar outras ideias semelhantes. Com isso, um grande número de ideias deve, 
ainda que não de modo atual e de uma só vez, estar presente em potência na mente. Além disso, a mente está normalmente apta a reavivar qualquer ideia conforme a necessidade do raciocínio ou do discurso. Assim, por exemplo, desde que tenhamos as ideias abstratas de triângulo e de equitaleralidade, a asserção falsa "todos os triângulos são equiláteros" pode imediatamente nos trazer à mente uma ideia de um triângulo não-equilátero particular mesmo se a ideia originalmente evocada fosse a de um triângulo equilátero. Em razão desta relação com outras ideias semelhantes enquanto mediadas através da resposta verbal original (que dessa maneira torna-se um "termo geral"), uma ideia particular torna-se uma "ideia abstrata ou geral", sendo capaz de representar, "deste modo imperfeito", uma classe inteira de objetos semelhantes.

Por comodidade terminológica, chamo de "conjunto reavivado" da ideia abstrata a ideia particular efetivamente suscitada pelo termo geral acrescida do conjunto mais amplo de ideias passíveis de serem reavidadas. Enquanto uma crença não-conceitualizada básica consiste simplesmente na ocorrência de uma ideia vívida, uma crença conceitualizada (isto é, uma cujo tipo Hume descreve como "contendo um predicado e um sujeito") consiste aparentemente na ocorrência de uma ou mais ideias vívidas associadas no interior do conjunto reavivado de uma ideia abstrata que fornece um "predicado" geral.

O terceiro elemento é a correção natural. Hume descreve este processo de maneira mais sistemática ao tratar do senso moral, quando o denomina de "correção [de nossos] sentimentos... para regular nossas noções abstratas" (T 3.3.1.21). Como enfatiza nesta passagem, entretanto, "correções como essa são comuns para todos os sentidos" (T 3.3.1.21). As similaridades entre as respostas tendem, naturalmente, em direção ao desenvolvimento de uma ideia abstrata. As diferenças entre elas, todavia, seja aquelas relativas ao estado das pessoas que respondem, seja aquelas 
relativas às condições de observação, resultarão muitas vezes em diferentes respostas para os mesmos estímulos (tanto no caso de uma única pessoa considera em diferentes momentos, quanto no caso de diferentes pessoas consideradas em um mesmo momento). Tais diferenças de resposta são, com frequência, incômodas para os indivíduos que as experimentam ou as observam, inclinandoos naturalmente à manutenção de uma maior uniformidade e acordo intrapessoal e interpessoal no que diz respeito às suas reações. Alcança-se isso principalmente pela gradual adoção e refinamento (através de uma convenção tácita) do que Hume chama de um "padrão" para julgar. A existência de padrões do juízo é mencionada por ele em contextos muito diferentes.

É possível notar, a partir dos exemplos de Hume, que o padrão de juízo para um senso-conceito consiste, em sua forma geral, numa perspectiva ou "ponto de vista" ideal a partir do qual se produzem certas respostas associado às habilidades ou "qualidades" ideais com as quais essas respostas são produzidas. Assim, para o caso das cores, Hume especifica os dois elementos constitutivos do padrão enquanto "objetos na luz do dia para o homem de olhos sadios" (ST 234). ${ }^{4}$ Quanto ao belo e ao feio nas artes, tais elementos são constituídos do ponto de vista do público-alvo (que "afasta" o homem que responde de "todo o preconceito") associado às qualidades constitutivas do "verdadeiro crítico", vale dizer, às qualidades parcialmente naturais e às parcialmente desenvolvidas: "um senso forte, unido a um sentimento delicado, aprimorado pela prática, e aperfeiçoado pela comparação" (ST 241). No caso particular do belo e do feio para a visão, ele acrescenta, a perspectiva ideal também inclui a distância adequada à visão do todo com o mínimo de prejuízo em relação aos seus detalhes ( $\mathrm{T}$ 
3.3.1.15). Os padrões morais, por sua vez, radicam sobre o que Hume denomina de "pontos de vista firmes e gerais" de todos que compõem o "estreito círculo" do indivíduo a ser julgado, juntamente com as qualidades da simpatia, os fortes mas delicados sentimentos morais e o entendimento mais abrangente das causas e efeitos que envolvem a vida dos homens ( $\mathrm{T}$ 3.3.1).

Em cada um desses casos, os homens consideram como o conjunto reavivado correto ou adequado da ideia abstrata, aquele que poderia resultar das classificações construídas em conformidade com o padrão e cuja adesão ensaiam ao menos na imaginação. Importa porém destacar que os homens não aderem a um padrão particular porque o tomam como antecipadamente correto em relação a uma finalidade estabelecida. Ao invés disso, o padrão torna-se correto porque é aquele para o qual os homens naturalmente convergem - normalmente por razões sólidas e compreensíveis - em relação à finalidade.

O ponto de vista ideal socialmente acordado e as qualidades respondentes que constituem o padrão de juízo, contudo, são dificilmente alcançados em sua plenitude - mesmo quando dizem respeito a certos casos da imaginação. Por esse motivo, em parte, os homens frequentemente desenvolvem, como um segundo modo de correção, "regras para julgar" a aplicação de um senso-conceito. Essas regras derivam normalmente da experiência de aplicações passadas da ideia abstrata e resultam satisfatórias ou insatisfatórias a partir do cotejo com o padrão. Talvez pela facilidade em alcançá-las, Hume não menciona regras específicas para julgar os padrões para juízo de cores, sons, sabores e odores, apesar de notar que "regras" da perspectiva espacial possam ser empregadas com o propósito de julgar qualidades primárias, tais como forma e tamanho. No que respeito ao belo e ao feio, porém, Hume assinala diversas "regras de arte" ou críticas, tais como os princípios da composição literária ou da 
trama dramática, cujo emprego pode antecipar e também explicar as respostas conferidas pelas verdadeiras críticas idealizadas, assim como servir de orientação aos artistas para a criação de trabalhos cuja aprovação se dá em conformidade com o padrão.

A atribuição relacional é o último elemento. E embora o conjunto reavivado de uma ideia abstrata desempenhe um papel crucial na determinação da natureza de um conceito humeano e no significado do termo geral associado a este conceito, Hume confere importantes concessões ao "costume... de atribuir certas relações às ideias" com independência da consulta ao conjunto reavivado. Essas relações atribuídas constituem o que agora se poderia chamar de papel inferencial dos conceitos. Assim, escreve Hume:

Ao falarmos de governo, igreja, negociação, conquista, raramente explicitamos em nossa mente todas as ideias simples que compõem essas ideias complexas. Observese entretanto que, apesar dessa imperfeição, podemos evitar dizer absurdos acerca desses temas, e somos cabazes de perceber qualquer incompatibilidade que haja entre as ideias, tão bem como se as compreendêssemos inteiramente. Assim, se, em vez de dizer que na guerra o mais fraco sempre recorrem à negociação, dissermos que eles sempre recorrem à conquista, o costume que adquirimos de atribuir certas relações às ideias, por continuar acompanhando essas palavras, fará que percebamos imediatamente o absurdo dessa proposição. ( $\mathrm{T}$ 1.1.7.14)

Esta susceptibilidade à relação inferencial atribuída através do costume não é, de nenhum modo, exclusiva dos senso-conceitos em Hume, tal como seus exemplos atestam, mas se aplica, em princípio, também a eles. Em sentido amplo, podemos pensar em termos de um papel conceitual que abrange não apenas as inferências socialmente aceitas, mas também outras operações mentais socialmente aceitas, incluindo nisso os sentimentos, as paixões e as volições. 
Como sugere esta breve explicação, Hume trata cada um dos sentidos como responsável pela origem de um ou mais conceitos que operam como senso-conceitos imediatos de seus respectivos sentidos. Esses conceitos - de AZUL, HUMOR, BELO, FEIO, VIRTUDE e VÍCIO ${ }^{5}$ - surgem mais diretamente dos sentidos, através dos processos de ativação repetida, generalização inicial, correção natural e atribuição relacional. Podemos considerar os conceitos de PONTO AZUL, HISTÓRIA ENGRAÇADA, BELA CASA e AÇÃO VIRTUOSA (todos empregados por Hume) como senso-conceitos mediatos na medida em que são constituídos pela aplicação de um sensoconceito imediato - seja pela aplicação a uma série particular de casos limitados, seja a uma relação particular com qualquer outra coisa. A ativação dos mais diversos sentidos (tanto do senso de humor, beleza e virtude quanto dos sentidos externos) também produz, ao que tudo indica, senso-conceitos mediatos segundo os graus particulares da qualidade em questão a exemplo da ATROCIDADE, para os grandes vícios, e da FALHA, para os menores. Esses serão generalizados enquanto resposta aos diferentes graus de intensidade de uma resposta mental repetidamente ativada para, a partir disso, serem corrigidos, na maioria dos casos, segundo um padrão e segundo regras, que os fazem adquirir suas próprias relações atribuídas.

\section{PROBABILIDADE ENQUANTO SENSO-CONCEITO}

Defendi em outras ocasiões que o conceito de causação de Hume enquadra-se, em grande medida, na caracterização dos senso-conceitos tal como aqui esboçado e que tratá-lo desse modo é pode esclarecer sua teoria da causação. No entanto, ao invés de explorar esta linha de raciocínio, pretendo defender que o conceito 
de probabilidade também é, na filosofia de Hume, um sensoconceito.Equeemboranãouseaexpressão "sensodeprobabilidade", ele aproxima-se bastante disso ao comparar explicitamente os raciocínios prováveis com a sensação e o sentimento estético:

Todo raciocínio provável não é senão uma espécie de sensação. Não é somente na poesia e na música que devemos seguir nosso gosto e sentimento, mas também na filosofia. (T 1.3.8.11)

De fato, a passagem sugere não apenas que a probabilidade seja análoga ao belo, mas também que a comparação lançará luz diretamente sobre nossa questão fundamental e que diz respeito a como a filosofia é julgada.

Não é difícil notar o que seria a sensibilidade primitiva que constitui o senso humeano de probabilidade: trata-se da capacidade de sentir a vividez, em seus variados graus, ao se conceber as ideias de como as coisas devem ser, ou ainda, podemos dizer seguindo Hume, ao conceber "questões de fato que são possíveis" (EHU 4.1). ${ }^{6}$ Razão pela qual, no trecho citado, ele continua:

Quando estou convencido de um princípio qualquer, é apenas uma ideia que me atinge com mais força; quando dou preferência a um conjunto de argumentos sobre outro, não faço mais que decidir, partindo daquilo que sinto, sobre a superioridade de sua influência. (T 1.3.811)

Este sentimento, segundo Hume, também frequentemente denominado de "sentimento de crença", constitui a mente daquele que crê na representação da ideia. Com efeito, é Hume quem declara ser "a crença mais propriamente um ato da parte sensitiva que da parte cogitativa de nossa natureza" 
( $\mathrm{T}$ 1.4.1.8), reforçando ainda mais a tese segundo a qual a capacidade de sentir uma crença é mais adequada para operar como um senso. As três fontes primárias deste sentimento são: a "memória", que transmite as crenças sobre o passado; "os sentidos", que transmitem as crenças sobre a existência contínua e distinta dos corpos externos; e "o raciocínio provável", que transmite as crenças sobre as questões de fato que nem são rememoradas nem estão presentes para os sentidos.

É importante enfatizar que, na passagem mencionada, Hume emprega o termo "provável" em sentido amplo, inspirado em Locke, que inclui em seu escopo não apenas os graus mais baixos de segurança mesclados a uma incerteza psicológica, mas também o mais alto grau de segurança a que Hume chama de "prova" que resulta de uma experiência difusa e uniforme e que exclui a incerteza ( $\mathrm{T}$ 1.3.11.2). A probabilidade, neste sentido amplo, difere apenas do "conhecimento" pensado em sentido estrito, também este inspirado em Locke, e que Hume trata como delimitado, em grande medida, na sua aplicação à matemática. Ao propor a tese segundo a qual Hume apela para o que é, no fundo, um "senso de probabilidade", lanço mão deste sentido amplamente inclusivo do termo "probabilidade". Cabe todavia notar que Hume também distingue um sentido mais estrito do termo, que esteja talvez em maior acordo com o uso comum, no qual a probabilidade envolve apenas parte da probabilidade tomada em sentido amplo, dizendo respeito aos mais baixos graus de segurança contrastados com a certeza de uma prova. Ele reconhece três versões ou tipos específicos de raciocínios que produzem esses graus baixos de segurança, chamando-os de: "probabilidade das chances", "probabilidades das causas" e "analogia" (T 1.3.11.2).

Pode-se facilmente distinguir, no desenvolvimento do conceito humeano de probabilidade, os mesmos quatro elementos que caracterizam o desenvolvimento dos outros sensoconceitos. Em primeiro lugar, a ativação repetida da capacidade 
de sentir os graus de vividez, isto é, os graus dos sentimentos de crença, ocorre ao se conceber, através da memória, dos sentidos ou do raciocínio provável, as questões de fato possíveis. Em segundo lugar, a similaridade entre os casos dessas respostas características conduz a mente humana à generalização inicial, formando uma ideia abstrata de probabilidade enquanto qualidade das questões de fato possíveis que são representadas pelas ideias vívidas. Como no caso de muitos outros sentidos humeanos, a mente humana também forma ideias abstratas de graus particulares de qualidade - incluindo, neste caso, tanto a prova quando o mais baixo grau de probabilidade - em resposta aos diferentes graus da resposta mental característica.

Em terceiro lugar, os sentimentos divergentes de probabilidade que dizem respeito a uma mesma questão de fato são, em muitos casos, corrigidos naturalmente por meio da referência a padrões de juízo. Hume indica que "o verdadeiro padrão de juízo" para a probabilidade das questões de fato consiste no ponto de vista da "experiência" extensiva (T 1.3.9.12) - um ponto de vista assumido pelo "homem sábio, que dosa sua crença em proporção à evidência" (EHU 10.4). Assim, ao dosar sua crença em proporção à evidência a partir da experiência, o indivíduo sábio terá desenvolvido a capacidade de resistir aos mecanismos de "credulidade" como uma resposta ao testemunho ( $\mathrm{T}$ 1.3.9.12), bem como a capacidade de resistir aos mecanismos que afetam a crença e que Hume designa de "probabilidade não filosófica" (T 1.3.13). Além disso, ao refletir sobre o sucesso e fracasso dos assentimentos e previsões passadas, o indivíduo sábio pode endossar e empregar certas "regras gerais" com o propósito de "impedir... o aumento... da crença a cada crescimento [momentâneo] da força e vividez de nossas ideias" como por vezes ocorre no "entusiasmo poético" (T 1.3.10.10-12). Ademais, espera-se que o homem sábio endosse e 
empregue regras matemáticas a fim de ponderar e balancear os graus de probabilidade, "subtraindo", como diz Hume, a força de uns poucos experimentos da força dos maiores. Essas regras matemáticas - subsequentes desenvolvimentos que encontrariam, sem dúvida, o endosso de Hume - permitem o desenvolvimento das relações de papel inferencial altamente articuladas atribuídas aos conceitos de graus particulares de probabilidade.

Entretanto, ainda que as qualidades do respondente ideal para os juízos de probabilidade sejam razoavelmente bem articuladas, não é fácil especificar em que consiste o ponto de vista ideal da "experiência". Se um conjunto de experiências é subconjunto de outro, podemos naturalmente submetê-lo àquele que o compreende. A extensão natural desta submissão a um ponto de vista idealizado tal como tudo experimentado pelos seres humanos até hoje, tudo que será experimentado, ou tudo que puder ser experimentado, todavia, possui muitas vezes pouco valor fora de uma sequência particular e bem definida. Por consequência, Hume parece disposto a relativizar muitos dos juízos de probabilidade de um corpo de evidência individual ou comum, admitindo que algo seja altamente provável em relação a um corpo de evidência, tomado em um momento por um indivíduo ou um grupo, e que seja menos provável em relação a outro. Podemos observar que ele admite uma certa quantidade de relativizações similares ligadas à moral: um traço que é uma virtude num conjunto de amplas circunstâncias culturais ou mesmo físicas (traços como habilidades militares ou o respeito à propriedade) pode ser menos virtuoso ou mesmo sequer virtuoso em diferentes circunstâncias culturais ou mesmo físicas.

Assim como Hume distingue um sentido amplo e um estrito para o termo "probabilidade", ele também o faz para o termo “imaginação". No sentido amplo, a imaginação é meramente a faculdade de possuir ideias não-mnemônicas ( $\mathrm{T}$ 1.3.9.19, n.22), 
visto que Hume recusa a tese racionalista segundo a qual a mente possui qualquer classe separada ou destacada de ideias do intelecto. Além disso, afirma serem funções da imaginação, pensada em sentido amplo, todos os modos pelos quais a mente possui e opera ideias não-mnemônicas - incluindo aí "juízos" e "raciocínios" (T. 1.3.7.5, n.20). Assim, em particular, o desenvolvimento dos conceitos de probabilidade e a produção, por meio deles, de juízos conceitualizados acerca da probabilidade da questões de fato possíveis, são funções da imaginação neste sentido amplo.? Isto decerto inclui aquelas questões gerais de fato descritas pelos sistemas filosóficos - contando entre eles o sistema de Hume.

\section{CONCEITOS NORMATIVOS}

A imaginação, assim, sente a probabilidade dos estados de coisas ao concebe-los com seus graus de vividez. Ela produz juízos de probabilidade conceitualizados que são corrigidos e aperfeiçoados através dos conceitos de probabilidade que desenvolve. Tais juízos estendem-se à probabilidade das questões de fato possíveis que são afirmadas pelos sistemas filosóficos. Mas isto não é tudo, pois Hume também afirma que a imaginação é o "juiz último" desses sistemas, o que implica uma avaliação mais especificamente normativa. A fim de entender como é possível esse tipo de avaliação para Hume, devemos primeiramente esboçar, de maneira breve, sua abordagem acerca dos conceitos normativos em geral, isto é, acerca dos conceitos prescritivos ou avaliativos. Alguns senso-conceitos, tais como AGUDO e AZUL, são claramente conceitos não-normativos para Hume. Outros são empregados, no entanto, ao menos em algum grau, como 
avaliações positivas ou negativas. O conceito HUMOR parece normativo ao menos num sentido moderado, na medida em que chamar algo de engraçado consiste em expressar, pelo menos num sentido comum, um tipo de aprovação. Os conceitos de BELO e FEIO são mais claramente normativos, sendo justo afirmar de quase qualquer coisa que, permanecendo inalterado tudo o mais, ela seria melhor ao ser mais bela do que nos casos em contrário. Os conceitos de VIRTUDE e VÍCIO são ainda mais normativos, ou, melhor dizendo, são ainda mais marcadamente normativos. Cada um deles, no entanto, envolve tipos distintos de valorização ou depreciação correspondentes — risível, estético ou moral, respectivamente. Além disso, podemos distinguir em cada caso os conceitos fundamentalmente normativos de Hume, que são tratados enquanto conceitos de valorização ou desvalorização primárias e cuja função consiste em estruturar todo um domínio normativo, dos conceitos normativos por derivação, os quais implicam uma avaliação que de algum modo depende da valorização ou depreciação fundamental. Conceitos como os de HOMEM SAGAZ, ARTISTA HABILIDOSO ou AÇÃO GENEROSA (todos utilizados por Hume), por exemplo, são normativos por derivação dessa maneira. Em contraste, os conceitos fundamentalmente normativos no domínio do risível, do estético e da moral são, ao menos para ele, também senso-conceitos imediatos: HUMOR ou SAGACIDADE, BELO e FEIO, VIRTUDE e VÍCIO, respectivamente.

Hume é naturalista no que diz respeito à normatividade, mas também o é em muitas outras questões. Ocorre que, em princípio, a normatividade de um conceito é algo que deve ser explicado ao invés de tratado como irredutível. 
Podemos distinguir, através da atenção minudente a suas anotações nos mais diversos contextos, quatro elementos que constituem, mais uma vez, estágios superpostos - para a constituição da normatividade completa de um conceito.

Primeiro, é preciso que haja uma apreciação ou depreciação compartilhada da qualidade destacada por um conceito, seja da qualidade relativa à própria pessoa seja daquela relativa aos outros. Esta apreciação ou depreciação compartilhada é frequentemente reforçada pela operação do que Hume chama de "simpatia", através da qual o reconhecimento dos sentimentos alheios é capaz de causar sentimentos similares no observador. Segundo, a apreciação ou depreciação compartilhada provoca, por meio das paixões, consequências interpessoais positivas ou negativas. A estreita relação de uma pessoa com um objeto belo ou com um indivíduo detentor de traços virtuosos, produz amor a essa pessoa, o que leva à "benevolência" - ao desejo de felicidade e à aversão ao sofrimento desta pessoa - e à realização dos "bons ofícios". De modo similar, mas numa linha ainda mais forte, Hume escreve que a incitação do orgulho e da humildade, do amor e do ódio, "é, talvez, o efeito mais importante da virtude e do vício sobre a mente humana" ( $\mathrm{T}$ 3.1.2.5). Com efeito, é justo afirmar que o livro II do Tratado, com sua extensa discussão sobre essas paixões, contém a maior parte da explicação naturalista sobre como e porque VIRTUDE e VÍCIO constituem conceitos normativos tão relevantes. Terceiro, a normatividade em sentido pleno exige daqueles que empregam um conceito, que aceitem o compromisso pessoal de aprovar, defender e promover a qualidade por ele 
valorizada, ou de desaprovar, rejeitar e impedir a qualidade desvalorizada. Sobre as virtudes, por exemplo, ele escreve:

O que é honroso, o que é imparcial, o que é decente, o que é nobre, o que é generoso, toma posse do coração e anima-nos a abraçá-lo e conservá-lo. (EPM 1.7)

Por fim, o termo geral de um conceito deve ser entendido como expressando ou "implicando", como um elemento de seu significado, um elogio ou condenação. Como Hume mesmo observa, o termo é "entendido em um bom [ou mau] sentido". Assim, ele escreve:

A palavra virtude, com seus equivalentes em todas as línguas, implica elogio, assim como a palavra vício, censura, e ninguém poderia, sem a impropriedade mais óbvia e grosseria, anexar reprovação a um termo que, na aceitação geral se entende num bom sentido, nem aplaudir quando o idioma requer desaprovação. (ST. Ver também EPM 1.10)

Que o termo adquira tais elementos de significação mostra que a apreciação ou depreciação compartilhada, as consequências interpessoais e o compromisso pessoal associado ao conceito são mutuamente reconhecidos e aceitos por aqueles que o empregam. Podemos perfeitamente pensar nisso como um tipo particular de papel conceitual, que consiste no que vimos Hume designar de "relações atribuídas". Neste caso, entretanto, as relações não são estritamente inferenciais no que diz respeito apenas às crenças, sendo também transições aceitas a partir da aplicação de um conceito a sentimentos favoráveis ou não-favoráveis, paixões e volições. 


\section{VERDADE E VERDADE PROVÁVEL ENQUANTO CONCEITOS EPISTEMICAMENTE NORMATIVOS}

No início de Uma Investigação sobre o Entendimento Humano, Hume descreve a tarefa principal da filosofia como sendo a de "estabelecer os fundamentos da moral, do raciocínio e da crítica" e "determinar a origem" das distinções entre "verdade e falsidade, vício e virtude, belo e feio". Além disso, ele caracteriza as "opiniões" não apenas como objetos do "assentimento", mas também da "aprovação" quando julgadas verdadeiras ( $\mathrm{T}$ 1.4.7.2; $\mathrm{T}$ 3.3.2.2). Obviamente, é matéria de grande controvérsia entre os filósofos até mesmo a determinação de quais sejam as distinções normativas fundamentais no domínio epistêmico, moral e estético. Tais aspectos do texto de Hume, contudo, sugerem que os conceitos de VERDADE e FALSIDADE (aplicável às crenças) estão, para ele, ao menos entre os conceitos fundamentalmente normativos do domínio epistêmico do valor, assim como VIRTUDE e VÍCIO (aplicável aos traços mentais) e BELO e FEIO (aplicável aos objetos, eventos e composições) estão entre os conceitos fundamentalmente normativos morais e estéticos, respectivamente.

VERDADE e FALSIDADE, no entanto, ao contrário dos últimos conceitos normativos mencionados, não constituem senso-conceitos para Hume. Em vez disso, ele observa, "a verdade é discernida meramente por meio das ideias, de sua justaposição e comparação" (T 3.1.1.4). Deixando de lado o caso particular de "conhecimento" rigoroso lockeano, Hume define a "verdade" em termos de correspondência enquanto "conformidade de nossas ideias dos objetos com a existência real destes" (T 2.3.10.2) e concordância "das ideias, consideradas como cópias, e os objetos 
que elas representam" ( $\mathrm{T}$ 2.3.3.5). A falsidade, ao contrário, consiste na carência de tal conformidade ou concordância. Mas de que maneira VERDADE e FALSIDADE chegam a ser conceitos normativos, implicando prescrição ou avaliação? Hume não põe a questão precisamente nesses termos, mas enfatiza e explica nossa apreciação da verdade na seção do Tratado intitulada "Da curiosidade, ou do amor à verdade". Ele inicia esta seção enunciando o seguinte:

Parece-me, no entanto, que fomos um pouco negligentes ao passar em revista tantas partes diferentes da mente humana, e examinar tantas paixões, sem levar uma só vez em consideração aquele amor à verdade, que é a fonte originária de todas as nossas investigações. (T 2.3.10.1)

Nessa seção, com efeito, Hume examina duas fontes bastante distintas de prazer e apreciação no que diz respeito à verdade. A primeira delas depende de dois elementos interdependentes: o prazer resulta do "exercício da inteligência" sobre uma "verdade" considerada como sendo de "alguma importância [prática]". A fim de confirma-lo, Hume observa uma interdependência análoga na caça e nos jogos entre os elementos de esforço e de valor prático. Porém, ao levarmos em conta o segundo elemento, somos lembrados que apreciamos (o que consideramos ser), em nós mesmos e nos outros, uma crença verdadeira, em parte por julgarmos serem tais crenças geralmente mais úteis, a nós e aos outros, assim como mais propícias à cooperação. A segunda fonte examinada por Hume consiste no prazer imediatamente agradável de possuir uma crença bem estabelecida. A vividez das ideias, ele diz, é sempre agradável de alguma maneira especialmente quando contrastada com a aridez da simples 
falta de crença ou da aflitiva oscilação entre incerteza e dúvida nas questões que se relacionam a nós o suficiente a ponto de despertar nosso interesse. Entretanto, devemos observar que tomar por verdadeiras nossas próprias crenças ou aquelas compartilhadas com outros é algo que reforça naturalmente este prazer - pois a explicação de Hume acerca da crença e da verdade, a saber, a crença de que uma dada crença é verdadeira, inclui literalmente a crença original como uma parte.

Podemos facilmente notar de que maneira as consequências interpessoais (a exemplo das atribuições de crença verdadeira como inspiração para o orgulho e o amor) e o compromisso pessoal (para a realização e propagação da crença verdadeira) resultam da apreciação compartilhada da verdade e da correspondente depreciação da falsidade. Consequentemente, também podemos notar de que maneira termo "verdade" passa a "ser tomado no bom sentido" como o indicador de um papel conceitual bem avalizado.

Apesar de o conceito de verdade propriamente dito não ser um senso-conceito, o de probabilidade ele mesmo, tal como o consideramos até aqui, não é normativo. Pois dizer que uma questão de fato possível (tal como "choverá amanhã") é provável não consiste, de modo algum, em exaltar ou condenar a questão de fato em si. Há, contudo, uma aplicação do conceito de probabilidade que possui um estatuto epistemicamente normativo, a saber: o senso-conceito mediato de verdade provável, que resulta da aplicação irrestrita do conceito de probabilidade às questões de fato singulares que são possíveis e que consistem na crença de ser verdadeiro. Com efeito, podemos chamar esta aplicação de "probabilidade" simpliciter, como Hume mesmo o faz, no contexto em que seu domínio é claramente entendido como o da verdade das crenças. Entretanto, dado 
que consideramos uma aplicação especial do senso-conceito de probabilidade entendido em seu sentido mais amplo, continuarei aqui a usar o termo "verdade provável". Existem, naturalmente, conceitos normativos negativos correspondentes da falsidade provável e da improbabilidade da verdade.

É natural supor que o conceito de verdade provável deriva sua normatividade tão-somente da normatividade mais fundamental do conceito de verdade - por exemplo, por meio de uma inferência que vai de $p$ é provavelmente verdadeiro para $p$ é verdadeiro. Mas é claro que o que se segue estritamente de uma premissa da forma pé provavelmente verdadeiro não é a crença de $p$ é verdadeiro, mas apenas de que é provavelmente verdade que $\mathrm{p}$ seja verdadeiro, e a questão acerca da origem do valor dessa probabilidade da verdade simplesmente retorna. Ao invés disso, minha sugestão consiste em afirmar que o conceito humeano de verdade provável adquire um status fundamentalmente normativo, mas que o faz em paralelo com o status normativo de verdade. Isso ocorre porque os próprios mecanismos há pouco esboçados para explicar por que uma verdade é apreciada, também operam diretamente para explicar por que achamos ser a posse de uma verdade provável, ao mesmo tempo, útil e imediatamente agradável - e quanto mais provável a verdade de uma crença, maior a apreciação compartilhada advinda dessas origens. O compromisso pessoal de Hume com a verdade provável enquanto um valor independente é expresso na seção final do livro I do Tratado, em que, apesar de saber que "dois mil anos, com interrupções tão longas e sob tão fortes desencorajamentos, são um período pequeno para permitir um aperfeiçoamento tolerável das ciências", escreve ele:

"Poderemos então ter esperanças de estabelecer um sistema ou conjunto de opiniões, que, se não verdadeiras (pois isso talvez seria esperar demais), sejam ao menos satisfatórias para a mente humana e resistam à prova do exame mais crítico." (T 1.4.7.14) 
Essa passagem sugere que Hume pode - e nós podemos sustentar a manutenção de um compromisso com a probabilidade da verdade em relação à evidência presente, mesmo nos momentos em que a própria verdade pareça ser uma meta por demais ambiciosa para se esperar no atual estado de investigação.

Se o que dissemos está correto, a VERDADE PROVÁVEL funciona como um senso-conceito mediato, mas como um que seja um conceito fundamentalmente normativo para Hume e que constitui, juntamente com a VERDADE, um dos dois conceitos positivos fundamentalmente normativos de valor epistêmico; além disso, um que seja adequado inclusive para julgar o valor epistêmico dos sistemas filosóficos, incluindo, tal como reconhecido mais uma vez na passagem citada, o próprio sistema de Hume. Não é, pois, surpresa que ele se refira, na Sinopse do Tratado às "probabilidades (...) de que a vida e a ação dependem completamente, e que nos guiam mesmo em nossas especulações mais filosóficas" (Abstract, 4). A imaginação guia e julga corretamente os sistemas filosóficos porque ela é a principal faculdade a partir da qual, através do desenvolvimento e refinamento de seu próprio senso inerente de probabilidade, somos capazes de julgar o valor epistêmico dos sistemas filosóficos ao julgar a probabilidade de serem eles verdadeiros. Ao utilizar seu senso de probabilidade e os conceitos que ele mesmo desenvolveu, Hume finalmente julga ser sua própria filosofia provavelmente verdadeira e, portanto, bem fundada.

\section{CONSEQUÊNCIAS PARA A EPISTEMOLOGIA HUMEANA}

A origem baseada no sentido [sense-based origin] e o status normativo do conceito de verdade provável de Hume 
tem consequências importantes para a epistemologia. Nesta conclusão, mencionarei três delas.

A primeira diz respeito à fonte e ao emprego dos princípios epistemicamente normativos substanciais acerca da verdade provável. Um traço característico da maneira pela qual o sensoconceito de Hume relaciona-se com a estética e a moral é que este não parte dos princípios normativos substanciais a priori. A título de exemplo, Hume explicitamente observa que "nenhuma das regras de composição é fixada por raciocínios a priori" (ST 4). E, de fato, sua teoria da mente não fornece nenhuma maneira de conhecer a priori, por meio dos princípios morais ou estéticos substanciais, o que é virtuoso ou belo. Ao invés disso, ele parte da sensibilidade moral e estética, que são corrigidas e refinadas a fim de produzir sentenças morais e estéticas. Ao endossar princípios moral e esteticamente normativos substanciais, tais princípios são mais propriamente sentenças que dependem do pronunciamento a posteriori do senso estético e do senso moral.

Questões semelhantes aplicam-se à verdade provável no domínio epistêmico. Dado que a VERDADE propriamente dita não é um senso-conceito, é perfeitamente possível haver princípios a priori que digam respeito a ela, sendo um exemplo o princípio segundo o qual as contradições não podem ser verdadeiras. As sentenças normativas substanciais acerca do que é provavelmente verdadeiro dependem, em última instância, no entanto, dos pronunciamentos a posteriori do senso de probabilidade e devem ser derivados destes. Ao contrário do que sugerem muitos intérpretes, Hume não possui qualquer princípio a priori a partir do qual inferências indutivas devam carecer de valor epistêmico a menos que a uniformidade da natureza possa ser estabelecida por um argumento não-circular. Além disso, 
quando a investigação de Hume acerca da mente humana suscita argumentos em favor das conclusões segundo as quais nossos raciocínios não são provavelmente verdadeiros, a diminuição da força de probabilidade que tais argumentos céticos possuem, contra os argumentos de probabilidade dos quais eles são alvos, é determinada precisamente por seu impacto considerado em relação ao senso de probabilidade então corrigido e refinado.

A segunda consequência diz respeito à diversidade irrepreensível em relação aos juízos de verdade provável. Embora os homens convirjam naturalmente em direção a um padrão de juízo para senso-conceitos, é inverossímil que o padrão acordado seja precisamente e tão bem definido a ponto de resolver toda possível diferença ao que possa surgir. Em princípio, portanto, isso deixa espaço para o que Hume chama de "diversidade irrepreensível” (ST 244). Assim, por exemplo, o padrão de belo não restringe os respondentes a um único temperamento:

Comédia, tragédia, sátira e ode têm, cada uma delas, seus partidários, que preferem uma espécie de escrita a todas as outras. (...) Tais preferências são inocentes e inevitáveis, e não seria razoável transformá-las em objetos de disputa, porque não há padrão pelo qual possam ser decididas. (ST 244)

Hume deixa espaço para diversidades irrepreensíveis similares que dizem respeito a juízos de probabilidade, inclusive em relação a uma mesma evidência. Frequentemente, é o que ocorre quando muitas considerações variadas, de tipos desiguais e incomensuráveis, mas em competição, devem ser equilibradas com sensibilidade, sendo especialmente predominante na probabilidade por analogia, o tipo de probabilidade menos 
suscetível à adoção das regras matemáticas fixas de juízo. Em seu Diálogos sobre a religião natural, por exemplo, Hume examina o argumento da analogia para a conclusão segundo a qual a causa ou as causas da ordem no universo assemelhamse à inteligência humana. Lá, em qualquer especificação do grau ou da natureza da semelhança, ele verifica a probabilidade da verdade submetida a um campo de diversidade irrepreensível bastante considerável e que resulta de uma abertura relativa ao temperamento doxástico do padrão de juízo para probabilidade. A moral da história, sugere Hume, é que o teísta filosófico ou o cético filosófico, que se distinguem principalmente em relação ao temperamento, devem aprender a conviver uns com os outros. ${ }^{8}$

A terceira consequência está ligada à resistência ao erro global, que é característica dos senso-conceitos em geral. Acerca da moral, Hume escreve o seguinte:

Deve-se observar que as opiniões dos homens, neste caso, carregam consigo uma autoridade peculiar, sendo, em grande medida, infalíveis. A distinção entre o bem e o mal morais se funda no prazer ou na dor que resulta da contemplação de um sentimento ou um caráter; e como esse prazer ou essa dor não podem ser desconhecidos da pessoa que os sente, segue-se que, em cada caráter, há tanto vício ou tanta virtude quanto cada um põe nele; é impossível nos enganarmos quanto a isso. ( $\mathrm{T}$ 3.2.8.8)

Assim como ele afirma que o último árbitro da moralidade é o senso moral da humanidade idealmente corrigido e refinado, também o último árbitro da probabilidade da verdade é este senso de probabilidade idealmente corrigido e refinado. ${ }^{9} \mathrm{Da}$ mesma maneira que é difícil conceber como toda a humanidade 
poderia estar sempre equivocada acerca de quais sejam as cores das coisas, ou quais são as coisas engraçadas ou belas, ou qual caráter é virtuoso, da mesma maneira é difícil conceber, segundo essa perspectiva, de que maneira toda a humanidade poderia estar sempre equivocada acerca da probabilidade relativa de um dado corpo de evidência experimental.

Todavia, Hume está correto ao descrever a "peculiar autoridade" do senso moral corrigido e refinado como "infalível" apenas "em grande medida". Os senso-conceitos são tão-somente resistentes, e não imunes, ao erro global. Mas não são apenas os padrões gerais de juízo que encontram grande dificuldade em ser aplicados adequadamente a um caso particular. O processo de desenvolvimento de um sensoconceito, uma vez investigada suas aplicações e refletido sobre seus resultados, também pode, no fim das contas, redundar no enfraquecimento de sua aplicação. Um aspecto relevante, embora não seja esse o ponto de vista de Hume, é o que de fato ocorre no caso dos juízos de cor derivados do sentido para cor [sense of color], pois a investigação cuidadosa convencenos que nenhuma qualidade correspondente às exigências dos conceitos para cor pode realmente existir. No início de Uma investigação sobre os princípios da moral, Hume menciona o caso daqueles que simulam recusar a realidade das distinções morais. No mais, isso inquestionavelmente acarreta um grande perigo que diz respeito, para ele, à probabilidade, quando então registra na seção final do Tratado, Livro I:

A visão intensa dessas variadas contradições e imperfeições da razão humana me afetou de tal maneira, e inflamou minha mente a tal ponto, que estou prestes a rejeitar toda crença e raciocínio, e não consigo considerar uma só opinião como mais provável ou verossímil que outras. ( $\mathrm{T}$ 1.4.7.8) 
Felizmente, no entanto, esse é o relato de uma situação episódica. Em última análise, os pronunciamentos que são resultados dos numerosos exercícios da razão são aprovados enquanto provavelmente verdadeiros, juntamente com os pronunciamentos dosmuitosexercícios damemóriaedossentidos, de acordo com seu "Princípio Fundamental" ["Title Principle"]:

Quando a razão é vívida e se combina com alguma propensão, deve receber o assentimento. Quanto não o é, não pode ter nenhum direito de atuar sobre nós. ( $\mathrm{T}$ 1.4.7.11)

Ainda que o momento de recusa de todas as distinções de probabilidade seja transitório, os argumentos que o suscitou exercem uma força permanente contra a probabilidade derivada das operações das faculdades que tais argumentos põem em questão. Por esta razão, Hume julga que nossas crenças, de alguma maneira, têm uma menor probabilidade de serem verdadeiras do que anteriormente supúnhamos, sendo isso o que ele pretende dizer com (um aspecto do) ceticismo mitigado.

Para Hume, a questão acerca de quanto, exatamente, da probabilidade de nossas crenças serem verdadeiras deveria ser subtraída pelas descobertas indutivas que nos lançam em meio à dúvida, é algo determinado, em última instância, por meio do próprio senso de probabilidade corrigido. Em relação a um âmbito limitado, é plausível tratar-se de uma questão de diversidade irrepreensível sobre a qual aqueles que possuem diferentes temperamentos filosóficos podem divergir inocentemente. Todavia, acredita Hume, todos podemos concordar que sua filosofia conserva ao menos 
uma considerável dimensão em que é provavelmente verdadeira com base em nossa evidência para tanto, sendo devidamente julgada, portanto, como epistemicamente valiosa - e isto segundo seu próprio juiz, a imaginação.

\section{NOTAS}

${ }^{1}$ Professor da New York University. Texto traduzido por André de Jesus Nascimento, professor da UEFS.

${ }^{2}$ A Treatise of Human Nature. Oxford: Oxford University Press, 2007. Ed. David F. Norton \& Mary Norton. Doravante, as citações serão expressas por T, seguidas do livro, parte, seção, e o número do parágrafo.

* Para as citações de Hume, utilizamos aqui a bem estabelecida tradução HUME, David. Tratado da natureza humana. São Paulo: UNESP, 2000. Trad. por Déborah Danowski. [Nota do tradutor]

3A palavra sense significa, em bom português, "senso", mas também "sentido". Diante das dificuldades de tradução, decidimos pelo emprego da palavra "senso" na maioria dos casos, reservado à palavra "sentido" suas ocorrências no plural, tais como "sentidos externos" e "órgãos dos sentidos". Nas demais situações, acrescentamos a expressão original. [Nota do tradutor]

4"Of the Standard of Taste", in: Essays Moral, Political, and Literary. Indianapolis: Liberty Fund, 1987. Ed. Eugene F. Miller. Citado como ST e seguido pelo número da página.

* Utilizamos a seguinte tradução: “Do padrão do gosto", in: HUME, David. A arte de escrever ensaio. São Paulo: Iluminuras, 2008. Trad. por Márcio Suziki e Pedro Paulo Pimenta. [Nota do tradutor]

${ }^{5}$ Seguirei aqui o padrão convencional que se vale de letras maiúsculas para enunciar nomes para conceitos. Assim, BELO consiste no conceito de belo. ${ }^{6}$ An Enquiry Concerning Human Understanding. Oxford: Clarendon Press, 2000. Ed. Tom L. Beauchamp. Citado como EHU, seguido pela seção e número do parágrafo. 
*Adotamos aqui a seguinte tradução para o português: HUME, David. Investigações sobre o entendimento humano e sobre os princípios da moral. São Paulo: UNESP, 2004. Trad. por José Oscar de Almeida Marques. [Nota do tradutor]

${ }^{7} \mathrm{O}$ sentido estrito de "imaginação" recobre o mesmo fenômeno que o sentido amplo, "excluindo apenas nossos raciocínios demonstrativos e prováveis" ( $\mathrm{T}$, 1.3.9.19 n.22). Dado que o raciocínio provável é uma das fontes principais do sentimento de probabilidade, podemos considerar que é a imaginação, em sentido amplo, mais do que a imaginação em sentido estrito, aquela julga a probabilidade (também em sentido amplo) das questões de fato possíveis. ${ }^{8}$ Conferir meu artigo "What's True about Hume's 'True Religion'?", in: Journal of Scottish Philosophy, 10.2 (Setembro, 2012), p. 199-220.

${ }^{9}$ Assim, por exemplo, Hume desconsidera o problema sobre se uma questão de fato possível, para a qual há "um número superior de chances iguais", é realmente mais provável de ocorrer, alegando tratar-se de um problema sobre "uma proposição idêntica" (T 1.3.11.8) para a qual a resposta é, trivialmente, "sim". Pois ele acaba de retratar a probabilidade das chances como a espécie particular de probabilidade que radica em "um número superior de chances iguais". Desse modo, perguntar se uma questão de fato possível e futura que possui uma tal característica é realmente mais provável de ocorrer consiste em sugerir um prospecto de erro ali onde nenhum não há nada prontamente disponível. 